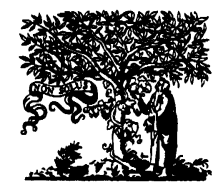

ELSEVIER

Technology and Disability 5 (1996) 235

Technology and Disability

\title{
Calendar
}

\section{November, 1996}

Workshop on Mobile Robotics for Rehabilitation, Athens, Greece.

Contact: ZENONSA, Mr. Nikos Katevas, Head of Research Department, Kanari 5, Glika Nera, 15344 Athens, Greece.

Phone: +3016041582, Fax: +301641051.

November 21-25, 1995

ASHA Annual Convention, Seattle, Washington.

Contact: ASHA Annual Convention, 10801 Rockville Pike, Rockville Pike, Rockville, MD 20852.

Phone: +1 3018975700 .

\section{August 31 to September 5, 1997}

8th World Congress of the International Rehabilitation Medicine Association IRMA, Kyoto, Japan.

Contact: Japan Convention Services, Inc., Nippon Press Center Bldg., 2-1, 2-chome, Uchisaiwai-cho, Chiyoda-ku, Tokyo 100, Japan.

\section{May 31 to June 4, 1998}

6th European Congress on Research in Rehabilitation, Berlin, Germany.

Contact: Congress Secretary ECRR-98, Mr. H. Kirsten, c/o BAR, Walter-Kolb-Str. 9-11, D-60594

Frankfurt/M, Germany.

Phone: +4969 60501810, Fax: +496960501837. 